\title{
ASPEK BIOLOGI RAJUNGAN (Portunus pelagicus) DI PESISIR KABUPATEN LAMPUNG TIMUR, PROVINSI LAMPUNG
}

\section{BIOLOGICAL ASPECTS OF THE CRAB (Portunus pelagicus) ON THE COAST OF EAST LAMPUNG REGENCY, LAMPUNG PROVINCE}

\author{
Meuthia Maharani Kanedi ${ }^{1}$, Mira Maulita ${ }^{1}$, Priyanto Rahardjo' \\ ${ }^{1}$ Prodi Teknologi Pengelolaan Sumberdaya Perairan Politeknik Ahli Usaha Perikanan \\ JI. AUP No. 1 Pasar Minggu-Jakarta Selatan; Telepon +21-7805030 Jakarta 12520 \\ E-mail : meuthiamhrni@gmail.com
}

\begin{abstract}
ABSTRAK
Salah satu potensi perikanan laut adalah rajungan (Portunus pelagicus). Rajungan (Portunus pelagicus) merupakan komoditas yang penting karena mempunyai nilai ekonomi tinggi dan permintaan pasar baik di dalam maupun luar negeri masih tinggi. Tujuan dilaksanakan praktik integrasi ini adalah untuk Menganalisis beberapa aspek biologi untuk mengetahui pola pertumbuhan sebagai acuan kajian stok rajungan dan Mengetahui aspek perikanan di Pesisir Kabupaten Lampung Timur, Provinsi Lampung mulai 2 September 2019 s/d 30 Oktober 2019. Metode yang digunakan dalam penelitian ini adalah metode penelitian deskriptif. Pengambilan data praktik meliputi penentuan hubungan lebar bobot karapas, nisbah kelamin, tingkat kematangan gonad, ukuran pertama kali tertangkap dan ukuran pertama kali matang gonad. Hasil praktik menunjukkan rajungan yang ada di pesisir Kabupaten Lampung Timur diperoleh dari hasil pengukuran sampel lebar-bobot rajungan sebanyak 1013 spesies dengan pola pertumbuhan alometrik negatif. Hasil nisbah kelamin $P$. pelagicus memperlihatkan bahwa 544 rajungan jantan (54\%) dan 469 rajungan betina (46\%) memiliki sex ratio $1: 0.862$. Persentase Tingkat kematangan gonad jantan $(46 \%)$ dan betina $(54 \%)$. Ukuran morfometrik nilai standar length at first maturity $(L m)$ yaitu $12.48 \mathrm{~cm}$. Dari hasil perhitungan diperoleh nilai Lc Total sebesar $13.23 \mathrm{~cm}$. Rajungan di Pesisir Kabupaten Lampung Timur biasanya ditangkap menggunakan alat tangkap Jaring Rajungan dan Bubu.
\end{abstract}

Kata Kunci : Rajungan; Lampung Timur, Pertumbuhan, Tingkat Kematangan Gonad

\section{ABSTRACT}

One of the potential marine fisheries is crab (Portunus pelagicus). Rajungan ( $P$. pelagicus) is an important commodity because it has high economic value and market demand both at home and abroad is still high. The purpose of implementing this integration practice is to Analyze several aspects of biology to find out growth patterns as a reference for swimming crab stocks in the East Lampung Regency, Lampung Province and Know the fisheries aspects in the East Lampung Regency, Lampung Province. The method used in this research is descriptive research method. Retrieval of practical data includes determining the relationship between carapace weight width, sex ratio, gonad maturity level, the size of the first caught and the size of the first gonad ripening. Practical results show that the small crab on the coast of East Lampung District was obtained from the measurement of the small crab width-weight sample of 1013 species with negative allometric growth patterns. The results of the genital ratio of $P$. pelagicus showed that 544 male crabs (54\%) and 469 female crabs (46\%) had a sex ratio of 1: 0.862. Percentage of male and female gonad maturity rates (46\%) and females (54\%). The morphometric size of the standard length at first maturity (Lm) is $12.48 \mathrm{~cm}$. From the calculation results obtained a total Lc value of $13.23 \mathrm{~cm}$. Rajungan on the Coast of East Lampung Regency is usually caught using the Rajungan and Bubu fishing gear.

Keywords : Portunus pelagicus; East Lampung; Catch 


\section{PENDAHULUAN}

Perikanan Indonesia mempunyai potensi sumberdaya ikan laut yang besar. Salah satu potensi perikanan laut tersebut adalah rajungan (Portunus pelagicus) (Yusfiandayani \& Sobari, 2011; Setiyawan \& Fitri, 2019). Rajungan (Portunus pelagicus Linnaeus, 1758) merupakan salah satu jenis kepiting (crab) dari famili Portunidae yang hidup di perairan dangkal hingga kedalaman $50 \mathrm{~m}$ dengan jenis substrat lumpur, pasir dan pasir berlumpur (Asphama et al., 2015; Nuraini et al., 2017; Prasetyo et al., 2014). Rajungan merupakan salah satu komoditas penting yang hingga saat ini sebagian besar produksinya diperoleh dari hasil penangkapan di alam (Waters, 2017; Istikasari et al., 2016).

Rajungan (Portunus pelagicus) merupakan komoditas yang penting karena mempunyai nilai ekonomi tinggi dan permintaan pasar baik di dalam maupun luar negeri masih tinggi (Kamrani et al., 2010; Wulandari \& Boesono, 2014; Adam et al., 2016; Damora \& Nurdin, 2016). Kepiting rajungan (Portunus pelagicus) merupakan jenis Crustacea yang temasuk hewan makanan, sehingga hewan ini disebut juga sebagai blue swimming crab (kepiting berenang) (Palupi, 2018; Prabawa et al., 2014). Penangkapan rajungan telah banyak dilakukan di beberapa perairan di Indonesia, salah satunya berada di perairan Lampung Timur.

Lampung Timur merupakan salah satu daerah produser rajungan di Indonesia dengan perikanan skala kecil dan produksi sangat fluktuatif. Hal ini berkaitan dengan ketersediaan stok dan penurunan produktivitasnya serta kapasitas rekrutmen terhadap stok yang dieksploitasi, terutama jika dihubungkan dengan intensitas eksploitasi yang tinggi di semua daerah distribusinya, yaitu mulai dari perairan pesisir yang dangkal sampai ke perairan tengah laut (off-shore). Dikhawatirkan akan terjadi penipisan stok dan gangguan pemanfaatannya dalam menunjang perekonomian nelayan serta sektor Kelautan dan Perikanan. Sementara itu, informasi tentang stok di daerah ini belum memadai, sehingga diperlukan berbagai opsi pengelolaan tanpa menunggu dilakukannya kajian stok untuk mengetahui statusnya (Kurnia \& Boer, 2014). Hal inilah yang melatarbelakangi penulis untuk melakukan kajian "Aspek Biologi Rajungan (Portunus pelagicus) di Pesisir Kabupaten Lampung Timur, Provinsi Lampung" dengan tujuan untuk menganalisis beberapa aspek biologi untuk mengetahui pola pertumbuhan sebagai acuan kajian stok rajungan dan Mengetahui aspek perikanan di Pesisir Kabupaten Lampung Timur, Provinsi Lampung mulai 2 September 2019 s/d 30 Oktober 2019.

\section{TUJUAN}

Menganalisis beberapa aspek biologi untuk mengetahui pola pertumbuhan sebagai acuan kajian stok rajungan dan Mengetahui aspek perikanan di Pesisir Kabupaten Lampung Timur, Provinsi Lampung.

\section{BAHAN DAN METODE}

Penelitian ini dilaksanakan selama 60 hari, terhitung mulai 2 September 2019 s/d 30 Oktober 2019 di wilayah Pesisir Kabupaten Lampung Timur, Provinsi Lampung. Metode yang digunakan selama praktik integrasi adalah Metode Survei dengan melakukan observasi di lapangan pada sampel rajungan yang menjadi target pengamatan. Data yang diambil adalah data primer dan data sekunder. Pemilihan responden dilakukan dengan metode random sampling. Pengambilan data biologi rajungan meliputi pengukuran lebar dan panjang karapas rajungan dan berat rajungan. Analisa hasil data yang didapat maka digunakan analisa deskriptif analitik dengan regresi sederhana untuk melihat hubungan antar variabel. 
Buletin JSJ, 2 (1), 2020, 49-56

Available online di: http://ejournal-balitbang.kkp.go.id/index.php/JSJ/index

\section{Hubungan Lebar-Berat}

Menurut pengamatan terhadap pertumbuhan rajungan dilakukan dengan cara mengukur lebar karapas dan berat total seluruh tubuhnya untuk menganalisa pola pertumbuhan rajungan dengan menggunakan analisis regresi. Panjang karapas diukur dengan menggunakan jangka sorong atau caliper (dengan ketelitian 0,05 mm). Bobot tubuh ditimbang dengan menggunakan timbangan digital (dengan ketelitian 0,01 gram). Panjang rajungan diukur dari anterior (tempat mata berada) ke arah posterior (tempat abdomen berada) sedangkan lebarnya diukur dari duri lateral terpanjang yang berada di sisi-sisi tubuhnya (Sunarto, 2012).

$$
\mathbf{W}=\mathbf{a L}^{\mathbf{b}}
$$

\section{Nisbah Kelamin}

Nisbah kelamin dihitung dengan cara membandingkan jumlah rajungan jantan dan rajungan betina (Tirtadanu \& Suman, 2018) dengan rumus:

$$
\text { Nisbah Kelamin }=\frac{J}{B}
$$

\section{Tingkat Kematangan Gonad}

Pengamatan terhadap tingkat kematangan gonad dilakukan secara morfologi yaitu dengan cara membuka karapas rajungan dan membandingkannya dengan ciri-ciri dan bentuk gonad sesuai dengan tabel klasifikasi tingkat kematangan gonad rajungan betina (Pane, Widiyastuti, \& Suman, 2017) dan jantan (Muhsoni \& Abida, 2009).

\section{Ukuran Pertama Kali Matang Gonad (Lm)}

Perhitungan panjang ikan pertama kali matang gonad (Lm) menggunakan persamaan Spearman-Karber yang dikembangkan oleh Udupa (1986) :

$$
\mathbf{m}=\mathbf{x}_{\mathbf{k}}+\frac{\mathbf{d}}{\mathbf{2}}-\left(\mathbf{d} \sum \mathbf{P} \mathbf{i}\right)
$$

\section{Ukuran Pertama Kali Tertangkap (LC)}

Pendugaan ukuran rajungan pertama kali tertangkap dilakukan dengan mengukur lebar karapas yang telah dikelompokkan berdasarkan kelas panjang total (sumbu $\mathrm{x}$ ). Dengan jumlah rajungan yang telah dinyatakan dalam persentase komulatif (sumbu y), dihitung dengan kurva logistik (kurva S). Untuk memperoleh nilai Lc (Length at first capture) yaitu dengan persentase sebesar $L 50 \%$ artinya lebar dimana $50 \%$ dari rajungan tertahan .

$$
\begin{gathered}
\mathbf{S L}=\frac{1}{\mathbf{1}+\exp (\mathbf{S 1}-\mathbf{S} 2 * \mathbf{L})} \\
\mathbf{L} \mathbf{5 0} \%=\frac{\mathbf{S 1}}{\mathbf{S 2}}
\end{gathered}
$$




\section{HASIL PEMBAHASAN}

\section{Aspek Biologi}

\section{Hubungan Lebar Bobot Rajungan}

Hasil tangkapan rajungan yang ada di pesisir Kabupaten Lampung Timur diperoleh dari hasil pengukuran sampel lebar-berat rajungan sebanyak 1013 spesies. Analisis hubungan lebar dan berat menggunakan data lebar karapas dan berat rajungan untuk mengetahui pola pertumbuhan spesies rajungan. Hubungan lebar berat rajungan secara total atau keseluruhan dan diproleh persamaan $\mathrm{W}=0.11 \mathrm{~L}^{2.79}$ dengan kisaran nilai b sebesar 2.79. Dari nilai $b$ yang diperoleh dan telah dilakukan uji $(\mathrm{a}=0.11)$ terhadap nilai $\mathrm{b}$ tersebut diketahui bahwa rajungan memiliki pola pertumbuhan alometrik negatif yaitu tolak $\mathrm{H}_{0}$ karena $b<3(b=$ 2.79), artinya pertambahan lebar karapas lebih cepat dari pada pertambahan berat sehingga rajungan cenderung melebar karapasnya. Grafik hubungan lebar-berat total rajungan (Portunus pelagiscus) dapat dilihat pada Gambar 1.

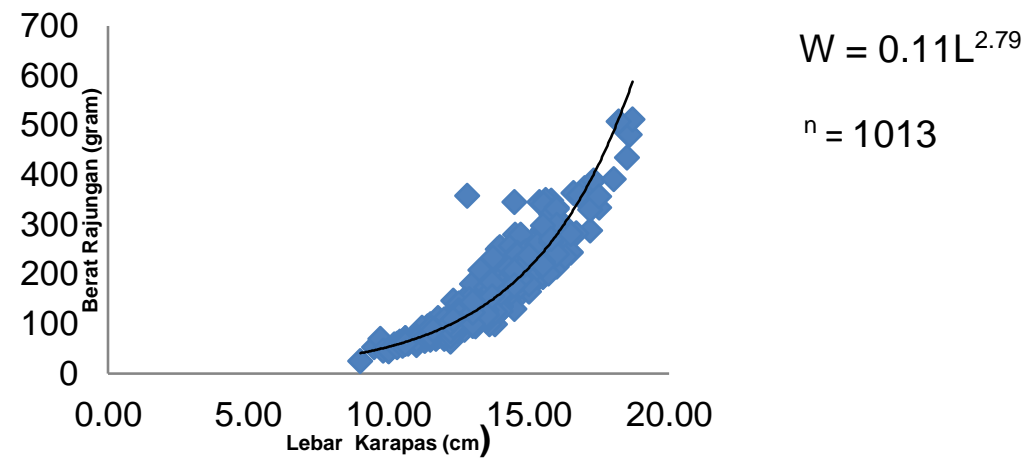

Gambar 1. Grafik Hubungan Lebar-Berat Total Rajungan (Portunus pelagicus)

\section{Nisbah Kelamin (Sex ratio)}

Penentuan jenis kelamin antara jantan dan betina dilakukan dengan cara mengamati warna gonad. Dari hasil pengamatan yang dilakukan terhadap 1013 ekor P. pelagicus Total diperoleh sebanyak 544 ekor $P$. pelagicus jantan, 469 ekor $P$. pelagicus betina. Hasil nisbah kelamin $P$. pelagicus memperlihatkan bahwa 544 rajungan jantan (54\%) dan 469 rajungan betina $(46 \%)$ memiliki sex ratio 1:0.862. Grafik persentasi sex ratio total rajungan dapat dilihat pada Gambar 2.

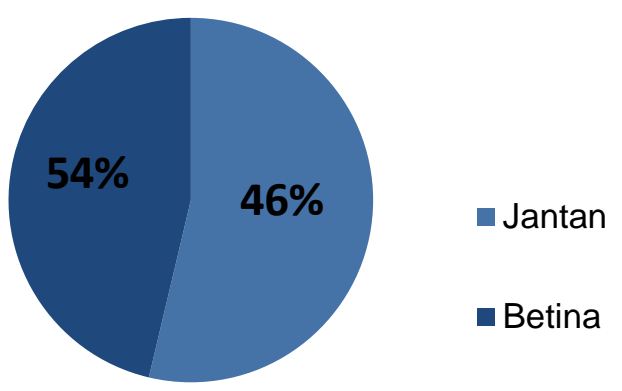

Gambar 2. Grafik Persentasi Sex Ratio Total Rajungan (Portunus pelagicus) 
Buletin JSJ, 2 (1), 2020, 49-56

Available online di: http://ejournal-balitbang.kkp.go.id/index.php/JSJ/index

\section{Tingkat Kematangan Gonad (TKG)}

Tingkat kematangan gonad jantan dapat dilihat dari ukuran dan warna gonad, sedangkan pada betina dilihat melalui ukuran, warna, dan ada tidaknya butiran telur pada gonad. Tingkat kemtangan gonad rajungan dapat dilihat pada Gambar 3.

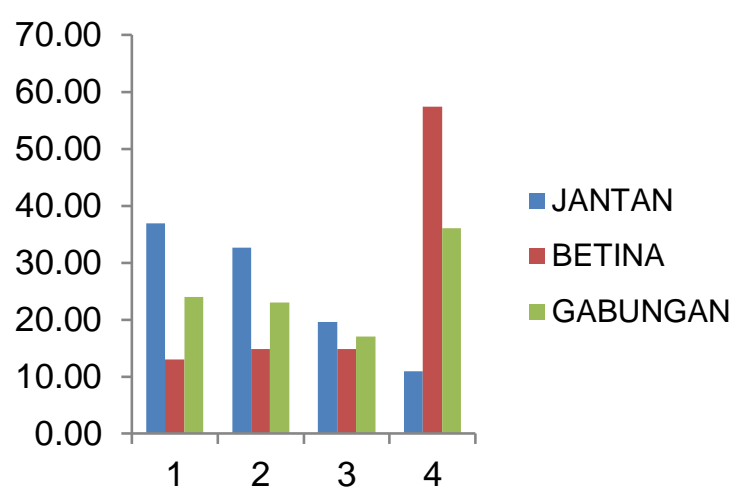

Gambar 3. Tingkat Kematangan Gonad Rajungan (Portunus pelagicus)

\section{Ukuran Pertama Kali Matang Gonad ( $L m)$}

Hasil pengamatan yang dilakukan untuk tingkat kematangan gonad dan sebaran ukuran lebar terhadap 100 ekor Portunus pelagicus. Diduga panjang pertama kali matang gonad yang ditentukan dengan metode pendekatan berdasarkan ukuran morfometrik nilai standar length at first maturity $(L m)$ yaitu $12.48 \mathrm{~cm}$. Dengan menggunakan taraf kepercayaan 95\%, maka batas kepercayaan untuk prediksi Portunus pelagicus yang sudah mulai matang gonad tersaji dalam Tabel 1.

Tabel 1. Lebar Portunus pelagicus Pada Saat Pertama Kali Matang Gonad (Lm) yang diduga:

\begin{tabular}{ccc}
\hline Jenis Kelamin & Lm $(\mathbf{c m})$ & Kepercayaan 95\% \\
\hline Gabungan & 12.48 & $12.29-12.67 \mathrm{Cm}$ \\
\hline
\end{tabular}

\section{Ukuran Pertama Kali Tertangkap (Lc)}

Perhitungan nilai Lc dilakukan dengan menggunakan data sebaran lebar dan jumlah rajungan pada setiap sebaran lebar terhdap 1.013 ekor sampel rajungan yang terdapat di Pesisir Kabupaten Lampung Timur dengan alat tangkap jaring rajungan dan bubu. Dari hasil perhitungan diperoleh nilai Lc Total sebesar $13.23 \mathrm{~cm}$. Nilai lebar pertama kali matang gonad $(\mathrm{Lm})$ rajungan total yaitu 12.48 , maka nilai Lc $>$ Lm yang artinya kondisi ini cukup baik untuk ditangkap, karena memberi kesempatan rajungan untuk matang gonad dan memijah terlebih dahulu. Grafik lebar pertama kali tertangkap rajungan (Portunus pelagicus) dapat dilihat pada Gambar 4. 


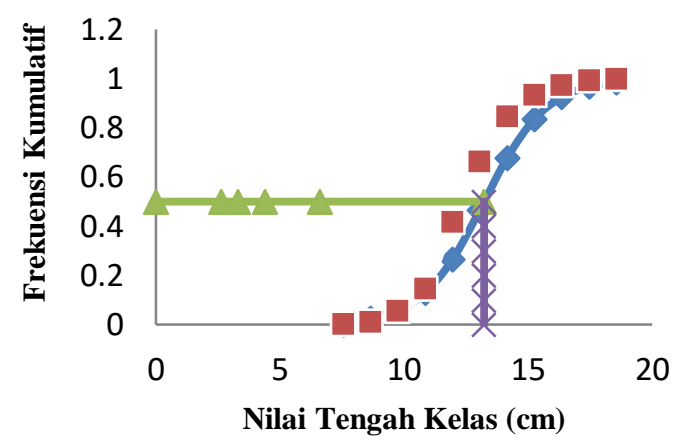

Gambar 4. Grafik Lebar Pertama Kali Tertangkap Rajungan (Portunus pelagicus)

\section{Aspek Perikanan}

\section{Alat Tangkap}

Terdapat dua macam alat utama untuk mengkap rajungan di perairan Lampung Timur yaitu jaring rajungan dan bubu lipat. Masing-masing alat tangkap biasanya dioperasikan pada lokasi yang berbeda, hal ini dimaksudkan agar jaring tidak dilanggar oleh bubu. Lokasi pengoperasian jaring dekat dengan pantai sedangkan bubu lebih jauh lagi. Pola musim tangkapan rajungan terdiri atas musim puncak, sedang dan paceklik. Musim puncak rajungan terjadi pada bulan Januari - Februari dan musim paceklik dari bulan Juli atau Agustus - September atau Oktober serta musim sedang berada diantaranya (Almaida et al., 2015).

\section{Armada Penangkapan}

Operasi penangkapan rajungan dilakukan 4-5 orang nelayan dengan menggunakan alat tangkap jaring maupun bubu. Untuk nelayan jaring masing-masing nelayan membawa jaring rajungan miliknya atau juragannya dan nelayan bubu rajungan membawa bubu lipat sebanyak 800-1500 bubu dalam satu trip, jumlah tersebut tergantung ketersediaan bubu yang dimiliki oleh nelayan.

Kapal atau perahu yang digunakan terbuat dari kayu. Ukuran kapal yang digunakan berbeda untuk kapal dengan alat tangkap jaring rajungan dan kapal dengan alat tangkap bubu. Kapal dengan alat tangkap jaring kejer berukuran 3-8 GT yang terbuat dari kayu ataupun fiber, dengan spesifikasi ukuran panjang (L) 8-10m, Lebar (B) 3,5m, Kedalaman (D) 2m, dan draft (d) $90 \mathrm{~cm}$, Sedangkan kapal dengan alat tangkap bubu sama-sama terbuat dari kayu namun berukuran lebih besar berkisar panjang (L) 10-15m, lebar (B) $4 \mathrm{~m}$, kedalaman (D) 2,5m, draft (d) $1 \mathrm{~m}$ dan berukuran 6-10 GT. Mesin yang digunakan berupa mesin diesel seperti kebanyakan yang digunakan adalah mesin diesel merk DongFeng, bertenaga 13,2-16,2 HP. Kapal motor yang digunakan adalah jenis Sopean yaitu kapal atau

perahu dengan bentuk buritan lancip, dan jenis kapal lain yang umum digunakan oleh nelayan setempat adalah jenis Kasoan yaitu kapal atau perahu dengan bentuk buritan kotak.

\section{KESIMPULAN}

Rajungan (Portunus pelagicus) yang didapatkan selama praktik integrasi sebanyak 1.013 ekor, terdiri dari 544 ekor jantan dan 469 ekor betina. Pertumbuhan rajungan bersifat Alometrik Negatif (Total), Alometrik Positif (Desa Margasari), Alometrik Negatif (Desa Sriminosari), Alometrik Negatif (Desa Labuhan Maringgai). Perbandingan jenis kelamin rajungan jantan dan rajungan betina adalah sebesar $54 \%$ dan $46 \%$ atau $1: 0.862$, hasil dari 
Buletin JSJ, 2 (1), 2020, 49-56

Available online di: http://ejournal-balitbang.kkp.go.id/index.php/JSJ/index

uji chi- kuadrat diperoleh bahwa ada perbedaan nyata antara populasi jantan dan betina rajungan (Portunus pelagicus).Tingkat kematangan gonad rajungan yang tertangkap ratarata berada pada TKG IV (36.00\%). Ukuran pertama kali matang gonad $(L m)$ yaitu $12.48 \mathrm{~cm}$, ukuran pertama kali rajungan tertangkap $(L c)$ yaitu $13.23 \mathrm{~cm}$, maka $L c>L m$ yang artinya kondisi ini cukup baik untuk ditangkap, karena memberi kesempatan rajungan untuk matang gonad dan memijah terlebih dahulu.

Rajungan di Pesisir Kabupaten Lampung Timur biasanya ditangkap menggunakan alat tangkap Jaring Rajungan dan Bubu. Nelayan di Pesisir Lampung Timur menggunakan kapal berukuran 3-8 GT yang terbuat dari kayu ataupun fiber. Operasi penangkapan dilakukan 4-5 orang nelayan.

\section{DAFTAR PUSTAKA}

Adam, A., Firman, F., \& Anwar, A. (2016). Model Pengelolaan Perikanan Rajungan Dalam Meningkatkan Pendapatan Nelayan di Kabupaten Pangkep. Jurnal Galung Tropika, 5(3), 203-209.

Asphama, A. I., Amir, F., Malina, A. C., \& Fujaya, Y. (2015). Habitat Preferences of Blue Swimming Crab (Portunus pelagicus) Species Complex. Aquacultura Indonesiana, 16(1), 10-15.

Damora, A., \& Nurdin, E. (2016). Beberapa aspek biologi rajungan (Portunus pelagicus) di perairan Labuhan Maringgai, Lampung Timur. BAWAL Widya Riset Perikanan Tangkap, 8(1), 13-20.

Istikasari, I., Kohar Mudzakir, A., \& Wijayanto, D. (2016). Analisis bioekonomi rajungan (Portunus pelagicus) menggunakan Pendekatan Swept Area dan Gordon-Schaefer di Perairan Demak.

Kamrani, E., Sabili, A. N., \& Yahyavi, M. (2010). Stock Assessment And Reproductive Biology Of The Blue Swimming Crab, Portunus pelagicus in Bandar Abbas coastal waters, northern Persian Gulf. Journal of the Persian Gulf, 1(2), 11-22.

Kurnia, R., \& Boer, M. (2014). Biologi Populasi Rajungan (Portunus pelagicus) dan Karakteristik Lingkungan Habitat Esensialnya Sebagai Upaya Awal Perlindungan di Lampung Timur. Jurnal Ilmu Pertanian Indonesia, 19(1), 22-28.

Muhsoni, F. F., \& Abida, I. W. (2009). Analisis Potensi Rajungan (Portunus pelagicus) di Perairan Bangkalan Madura. Embryo, 6(2), 140-147.

Nuraini, S., Prihatiningsih, P., \& Hartati, S. T. (2017). Parameter Populasi Dan Selektivitas Rajungan (Portunus pelagicus) Yang Tertangkap Dengan Beberapa Jenis Alat Tangkap Di Teluk Jakarta. Jurnal Penelitian Perikanan Indonesia, 15(4), 287-295.

Palupi, R. D. (2018). Komposisi ukuran kepiting Rajungan (Portunus pelagicus) berdasarkan fase bulan di Perairan Lakara, Konawe Selatan, Sulawesi Tenggara. Jurnal Manajemen Sumber Daya Perairan, 1(3).

Pane, A. R. P., Widiyastuti, H., \& Suman, A. (2017). Parameter Populasi Dan Tingkat Pengusahaan Rajungan (Portunus pelagicus) di Perairan Asahan, Selat Malaka. Bawal Widya Riset Perikanan Tangkap, 9(2), 93-102.

Prabawa, A., Riani, E., \& Wardiatno, Y. (2014). Pengaruh Pencemaran Logam Berat Terhadap Struktur Populasi Dan Organ Tubuh Rajungan (Portunus pelagicus, Linn). 
Jurnal Pengelolaan Sumberdaya Alam dan Lingkungan (Journal of Natural Resources and Environmental Management), 4(1), 17.

Prasetyo, G. D., Fitri, A. D. P., \& Yulianto, T. (2014). Analisis daerah penangkapan rajungan (Portunus pelagicus) berdasarkan perbedaan kedalaman perairan dengan jaring arad (mini trawl) di Perairan Demak. Journal of Fisheries Resources Utilization Management and Technology, 3(3), 257-266.

Setiyawan, H. A., \& Fitri, A. D. P. (2019). Pendugaan Stok Sumberdaya Rajungan Di Perairan Tegal Jawa Tengah. Jurnal Perikanan Tangkap: Indonesian Journal of Capture Fisheries, 2(3), 37-44.

Sunarto, S. (2012). Karakteristik Bioekologi Rajungan (Portunus pelagicus) Di Perairan Laut Kabupaten Brebes. Institut Pertanian Bogor (IPB).

Tirtadanu, T., \& Suman, A. (2018). Aspek Biologi, Dinamika Populasi Dan Tingkat Pemanfaatan Rajungan (Portunus pelagicus Linnaeus, 1758) Di Perairan Kotabaru, Kalimantan Selatan. Jurnal Penelitian Perikanan Indonesia, 23(3), 205-214.

Waters, I. K. (2017). Aspek Biologi, Dinamika Populasi Dan Tingkat Pemanfaatan Rajungan (Portunus pelagicus Linnaeus, 1758) Di Perairan Kotabaru, Kalimantan Selatan Biological Aspect, Population Dynamics And Exploitation Rate Of Blue Swimming Crab (Portunus pelagicus Linnaeus, 1758).

Yusfiandayani, R., \& Sobari, M. P. (2011). Aspek Bioteknik dalam Pemanfaatan Sumberdaya Rajungan di Perairan Teluk Banten. Jurnal Teknologi Perikanan dan Kelautan, 2(1), 71-80. 